\title{
Left-Sided Congenital Diaphragmatic Hernia with Multiple Congenital Cardiac Anomalies, Hernia Sac, and Microscopic Hepatic Heterotopia: A Case Report
}

\author{
Maria Arafah, ${ }^{1}$ Deena T. Boqari, ${ }^{2}$ and Khaled O. Alsaad ${ }^{2,3}$ \\ ${ }^{1}$ Department of Pathology, King Khalid University Hospital, College of Medicine, King Saud University, Saudi Arabia \\ ${ }^{2}$ Department of Pathology and Laboratory Medicine, King Abdulaziz Medical City, Saudi Arabia \\ ${ }^{3}$ The College of Medicine, King Saud bin Abdulaziz University for Health Sciences and King Abdullah International Research Centre, \\ P.O. Box 22490, Riyadh 11426, Saudi Arabia
}

Correspondence should be addressed to Khaled O. Alsaad, saadkh@ngha.med.sa

Received 7 September 2010; Accepted 19 January 2011

Academic Editor: Marco Volante

Copyright ( 2011 Maria Arafah et al. This is an open access article distributed under the Creative Commons Attribution License, which permits unrestricted use, distribution, and reproduction in any medium, provided the original work is properly cited.

\begin{abstract}
Congenital diaphragmatic hernia is a common congenital anomaly of uncertain etiology. Its association with multiple congenital anomalies in various organs is well recognized and antenatal radiological evidence of congenital diaphragmatic hernia warrants thorough evaluation to detect other anomalies, some of which can be life threatening. Rarely, heterotopic hepatic tissue is identified in the hernia, a rare pathological finding, exhibiting more than one macroscopic and microscopic characteristics, and always associated with cardiac congenital anomalies. Herein, we report a case of left-sided microscopic heterotopic hepatic tissue in a congenital diaphragmatic hernia in an infant with multiple cardiac congenital anomalies, but with preserved pericardium.
\end{abstract}

\section{Introduction}

Congenital diaphragmatic hernia $(\mathrm{CDH})$ is a common, lifethreatening congenital anomaly with an incidence ranging between 1 in 2000 and 1 in 5000 live birth [1]. The pathogenesis of $\mathrm{CDH}$ remains unclear, and its association with various concurrent congenital anomalies and variable pathological patterns and clinical presentation suggests that $\mathrm{CDH}$ is a result of multiple, complex developmental abnormalities [2]. It is estimated that associated congenital anomalies present in 30 to $40 \%$ of the cases of $\mathrm{CDH}$ [3], of which the most common are those of cardiac, urinary tract, gastrointestinal tract and central nervous system defects, as well as skeletal and neural tube defects $[4,5]$. Heterotopic liver tissue in $\mathrm{CDH}$ is rare and can be present in different macroscopic and microscopic forms. Microscopic heterotopic hepatic tissue in $\mathrm{CDH}$ is a very uncommon finding and almost always associated with cardiac congenital anomalies, particularly absence of the pericardium $[6,7]$. We report a case of a left-sided $\mathrm{CDH}$ with a microscopic heterotopic hepatic tissue and multiple cardiac congenital malformations but with a preserved pericardium.

\section{Case Report}

A full-term infant boy was delivered spontaneously and vaginally after an uneventful pregnancy. Antenatal ultrasound revealed left $\mathrm{CDH}$. His Apgar score was 6 and 7 at 1 and 5 minutes, respectively. He immediately developed respiratory distress and was intubated and transferred to the neonatal intensive care unit. Chest X-ray confirmed the left-sided $\mathrm{CDH}$ and showed pouching out of the loops of the large bowel, mediastinal shift to the right, and right lung hypoplasia (Figure 1). Initial echocardiogram revealed a small patent ductus arteriosus with no other cardiac congenital anomalies. At the age of 14 days, the infant underwent a surgical repair of the $\mathrm{CDH}$, of which the hernia was reduced back into the abdomen, and the hernia sac was excised. Intraoperatively, both lobes of the liver were intraabdominal. 


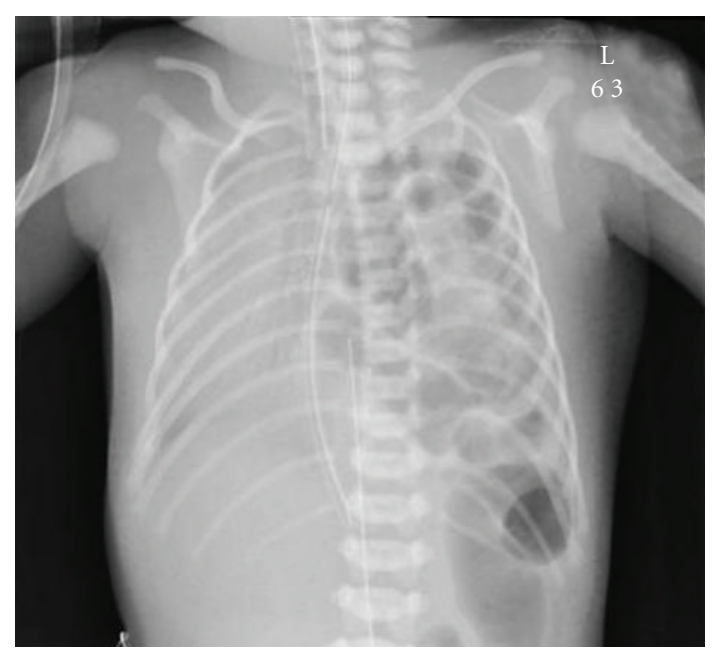

FIgure 1: Chest X-ray shows left-sided congenital diaphragmatic hernia with herniating loops of large bowel into the right hemithorax.

Grossly, the specimen consisted of a smooth, thick, and transparent sac-like structure measuring $4.5 \mathrm{~cm}$ in the maximum dimension. Multiple small tan-brown dark foci were noted in the sac-like structures, but no solid areas or papillary projections were obvious. Histological examination of formalin-fixed, paraffin embedded $5 \mu \mathrm{m}$, hematoxylin and eosin-stained sections showed vascularized fibrous tissue lined by bland mesothelial cells. Sections from the dark foci showed microscopic heterotopic hepatic tissue (Figure 2(a)). The hepatocytes were arranged in thin plates and focally in solid sheets. Congested sinusoidal spaces lined by flat Kupffer cells were seen separating the hepatic plates (Figure 2(b)). The hepatocytes showed a moderate degree of hydropic degeneration (ballooning), and focal canalicular cholestasis was noted. Areas recapitulating portal tracts were focally noted in the heterotopic hepatic tissue, but lacked intrahepatic arterioles. Areas in which florid cholangiolar proliferation, associated with mixed inflammatory cell infiltrate were identified (Figure 2(c)). The inflammatory cells, were predominantly lymphocytes and neutrophils; scattered eosinophils were also noted. Extramedullary hematopoiesis was noted. Immunohistochemically, the hepatocytes were strongly reactive for Hep Par-1 antibody (clone OCH1E5, dilution 1:50, Dako, Denmark) (Figure 2(d)). No heterotopic tissue other than hepatic tissue was identified.

The postoperative clinical course was complicated by Pseudomonas aeruginosa pneumonia. The patient was intubated and readmitted to the neonatal intensive care unit, where he was successfully treated with antibiotics. Further clinical and radiological work up revealed a patent foramen ovale and ventricular septal defect. The pericardium was unremarkable.

\section{Discussion}

The diaphragm is formed by the fusion of several embryonic components which include the septum transversum, pleuroperitoneal membranes, esophageal mesentery, and body wall mesoderm. As proposed by the work of Kluth et al. $[8,9]$, the development of the diaphragm is divided into two phases (1) the development of the diaphragmatic pericardium and (2) the development of the pleural cavity and the closure of the pleuroperitoneal canal (PPC). In the normal embryogenesis, the septum transversum separates the pericardial and the peritoneal cavities as it fuses dorsally with the mesodermal tissue surrounding the foregut. As this occurs, the PPC remains patent, connecting the pleural spaces and peritoneal cavity [10]. The pathogenesis of $\mathrm{CDH}$ is still not fully understood, and until recently, the general hypothesis is that the defect in $\mathrm{CDH}$ results from failure of complete closure of the PPC at the embryonic period 8th10th gestational week, which is an essential embryological step that completes the formation of the primitive fetal diaphragm [9].

The liver primordium appears in the 4 th gestational week, as an outgrowth of the endodermal epithelium at the distal end of the foregut, known as hepatic diverticulum, which consists of proliferating cell strands that penetrate the septum transversum. Iritani [11] indicated that a posthepatic mesenchymal plate (PHMP), which is the mesenchymal tissue that appears dorsal to the liver and ventral to the peritoneal canal, plays a cardinal role in the development of the diaphragm, and its growth is responsible for the closure of the PPC. The work of Kluth et al. [8, 9] using a nitrofen-induced rat model to study the cellular mechanisms of $\mathrm{CDH}$ showed failure of normal growth of the PHMP. Recent advances in cytogenetic analysis revealed various chromosomal aberrations and their association with $\mathrm{CDH}$, and minimally deleted region for $\mathrm{CDH}$ has been identified on chromosome 15q26.1-26.2 [12]. COUP-TFII, a member of nuclear receptors, is one of the genes located within this region. COUP-TFII is expressed in the primitive foregut mesenchyme, the developing PHMP, developing lung, and the septum transversum, the components that are important for the formation of the diaphragm. As elegantly demonstrated by the work of You et al. [13], ablation of COUP-TFII leads to abnormal development of PHMP and might play a critical role in the development of diaphragmatic hernia in mice. Therefore, it is likely that COUP-TFII contributes to the formation of $\mathrm{CDH}$ in individuals with $15 \mathrm{q}$ deletions.

Heterotopic liver tissue was reported in various organs, such as gallbladder, adrenal gland, small intestine, heart and lung as well as pleura and pericardium [14-19]. Collan at al [20] classified abnormally positioned liver tissue into four types: (1) accessory liver lobe that can reach a considerable size and is attached to the liver by a stalk, (2) small accessory liver lobe, which is attached to the liver but is usually small (10-30 grams in weight), (3) ectopic liver without any connection with it, and (4) microscopic ectopic liver. Types 2 and 3 have been reported to occur in association with $\mathrm{CDH}$ $[21,22]$.

Microscopic heterotopic liver tissue in a sac of a diaphragmatic hernia was rarely reported. To the best of our knowledge, only two cases are described in the English literature $[6,7]$, both of which were associated with congenital absence of the pericardium, along with other congenital 


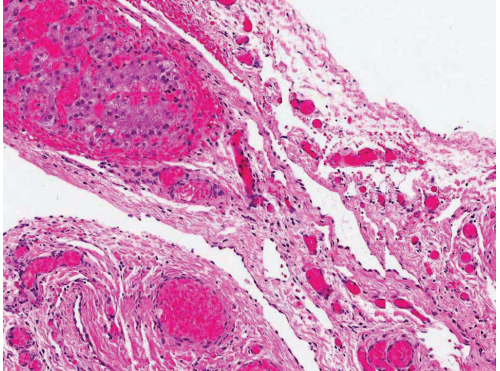

(a)

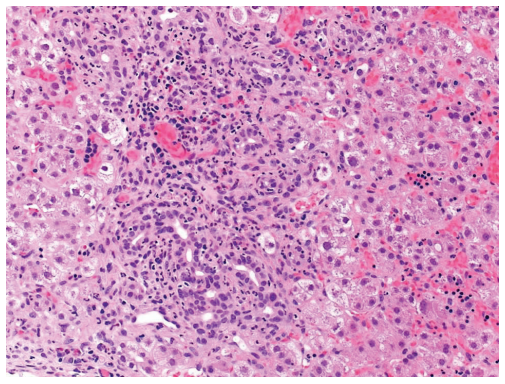

(c)

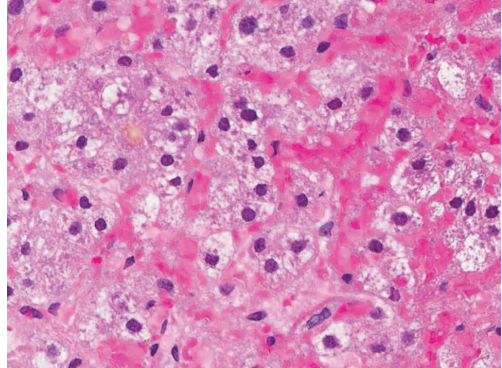

(b)

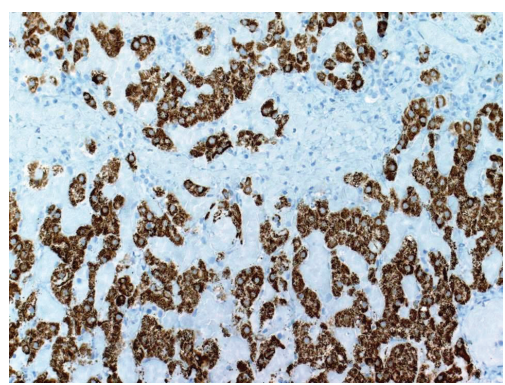

(d)

Figure 2: (a) Vascularized hernia sac with foci of heterotopic hepatic tissue. (b) Congested sinusoidal spaces separating the hepatic plates. (c) Areas of cholangiolar proliferation with accompanying mixed inflammatory cell infiltrate were seen. Note the mild hydropic change in the hepatocytes and the extramedullary hematopoiesis. (d) Immunexpression of Hep Par-1 in the heterotopic hepatocytes (original magnification (a) X100; (b) X400; (c) X200, (d) X200).

cardiac anomalies. The current case, as well as the previous two cases, is characterized by the presence of thick hernia sac containing microscopic foci of hepatic tissue. The hepatic tissue is considered heterotopic because it is histologically normal tissue found in an abnormal anatomical location. A recent report described a case of $\mathrm{CDH}$ in an infant, of which the left attenuated side of the liver formed a part of the dome of the hernia sac, and the wall of the hernia sac contained cord-like structures histologically confirmed to be liver tissue [23]. The association between $\mathrm{CDH}$ and congenital cardiac anomalies, including absent pericardium, is well recognized. Despite the presence of patent foramen ovale and ventricular septal defect in the current case, the pericardium was intact, a finding that has not been reported before in association with the presence of microscopic heterotopic liver tissue in a $\mathrm{CDH}$. This emphasizes the diversity of possible mechanisms of $\mathrm{CDH}$ as well as its clinical consequences and outcome.

\section{Acknowledgments}

The authors thank Mr. Nikolaos Chantziantonios for his assistance in the manuscript preparation. The authors declare no conflict of interests or financial support.

\section{References}

[1] M. R. Langham, D. W. Kays, D. J. Ledbetter, B. Frentzen, L. L. Sanford, and D. S. Richards, "Congenital diaphragmatic hernia: epidemiology and outcome," Clinics in Perinatology, vol. 23, no. 4, pp. 671-688, 1996.
[2] T. Ozdogan, C. Durakbasa, M. Mutus, and M. Iscen, "Congenital diaphragmatic hernia: a 4-year experience in a single centre," African Journal of Paediatric Surgery, vol. 7, no. 2, pp. 105-106, 2010.

[3] Y. Sweed and P. Puri, "Congenital diaphragmatic hernia: influence of associated malformations on survival," Archives of Disease in Childhood, vol. 69, no. 1, pp. 68-70, 1993.

[4] K. Vanamo, "A 45-year perspective of congenital diapbragmatic hernia," British Journal of Surgery, vol. 83, no. 12, pp. 1758-1762, 1996.

[5] G. M. Enns, V. A. Cox, R. B. Goldstein, D. L. Gibbs, M. R. Harrison, and M. Golabi, "Congenital diaphragmatic defects and associated syndromes, malformations, and chromosome anomalies: a retrospective study of 60 patients and literature review," American Journal of Medical Genetics, vol. 79, no. 3, pp. 215-225, 1998.

[6] A. A. Deutsch, K. N. Brown, N. V. Freeman, and D. A. Stanley, "A case of diaphragmatic hernia, absent pericardium, and hamartoma of liver," British Journal of Surgery, vol. 59, no. 2, pp. 156-158, 1972.

[7] Y. Patel, J. McNally, and P. Ramani, "Left congenital diaphragmatic hernia, absent pericardium, and liver heterotopia: a case report and review," Journal of Pediatric Surgery, vol. 42, no. 5, pp. e29-e31, 2007.

[8] D. Kluth, P. D. Losty, J. J. Schnitzer, W. Lainbrecht, and P. K. Donahoe, "Toward understanding the developmental anatomy of congenital diaphragmatic hernia," Clinics in Perinatology, vol. 23, no. 4, pp. 655-669, 1996.

[9] D. Kluth, R. Keijzer, M. Hertl, and D. Tibboel, "Embryology of congenital diaphragmatic hernia," Seminars in Pediatric Surgery, vol. 5, no. 4, pp. 224-233, 1996. 
[10] M. Hiradfar and S. Sadeghipoor, "Intrathoracic testicular ectopia in congenital diaphragmatic hernia," Asian Journal of Surgery, vol. 29, no. 4, pp. 303-305, 2006.

[11] I. Iritani, "Experimental study on embryogenesis of congenital diaphragmatic hernia," Anatomy and Embryology, vol. 169, no. 2, pp. 133-139, 1984.

[12] M. Klaassens, M. Van Dooren, H. J. Eussen et al., "Congenital diaphragmatic hernia and chromosome 15q26: determination of a candidate region by use of fluorescent in situ hybridization and array-based comparative genomic hybridization," American Journal of Human Genetics, vol. 76, no. 5, pp. 877-882, 2005.

[13] L. R. You, N. Takamoto, C. T. Yu et al., "Mouse lacking COUP-TFII as an animal model of Bochdalek-type congenital diaphragmatic hernia," Proceedings of the National Academy of Sciences of the United States of America, vol. 102, no. 45, pp. 16351-16356, 2005.

[14] L. Boyle, M. V. E. Gallivan, B. Chun, and E. E. Lack, "Heterotopia of gastric mucosa and liver involving the gallbladder. Report of two cases with literature review," Archives of Pathology and Laboratory Medicine, vol. 116, no. 2, pp. 138142, 1992.

[15] H. Brustmann, "Heterotopic liver in the right cardiac auricle," Annals of Diagnostic Pathology, vol. 6, no. 4, pp. 248-249, 2002.

[16] F. S. Buck and M. N. Koss, "Heterotopic liver in an adrenal gland," Pediatric Pathology, vol. 8, no. 5, pp. 535-540, 1988.

[17] A. Mendoza, J. Voland, P. Wolf, and K. Benirschke, "Supradiaphragmatic liver in the lung," Archives of Pathology and Laboratory Medicine, vol. 110, no. 11, pp. 1085-1086, 1986.

[18] J. R. Newland, R. S. Markin, R. B. Wilson, and J. W. Jones, "Heterotopic liver of the jejunum. Report of a case and a review," Journal of Clinical Gastroenterology, vol. 11, no. 4, pp. 461-463, 1989.

[19] R. I. Mehta, C. K. Lai, S. Kee, and M. C. Fishbein, "Intrapulmonary ectopic liver after orthotopic heart transplantation," Archives of Pathology and Laboratory Medicine, vol. 134, no. 7, pp. 1060-1062, 2010.

[20] Y. Collan, A. Hakkiluoto, and J. Hastbacka, "Ectopic liver," Annales Chirurgiae et Gynaecologiae, vol. 67, no. 1, pp. 27-29, 1978.

[21] H. A. Beiler, C. Sergi, G. Wagner, and Z. Zachariou, "Accessory liver in an infant with congenital diaphragmatic hernia," Journal of Pediatric Surgery, vol. 36, no. 6, p. E7, 2001.

[22] A. Bedii Salman, "Left-sided congenital diaphragmatic hernia associated with intrathoracic ectopic liver lobule," European Journal of Cardio-Thoracic Surgery, vol. 21, no. 3, pp. 558-560, 2002.

[23] S. Sharma, R. Jain, M. K. Singh, and D. K. Gupta, "A case of congenital diaphragmatic hernia with a hernia sac attached to the liver: hints for an early embryological insult," Journal of Pediatric Surgery, vol. 42, no. 10, pp. 1761-1763, 2007. 


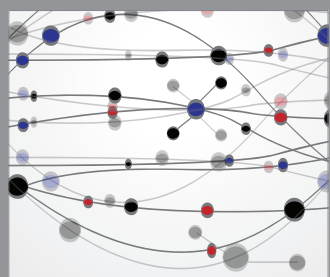

The Scientific World Journal
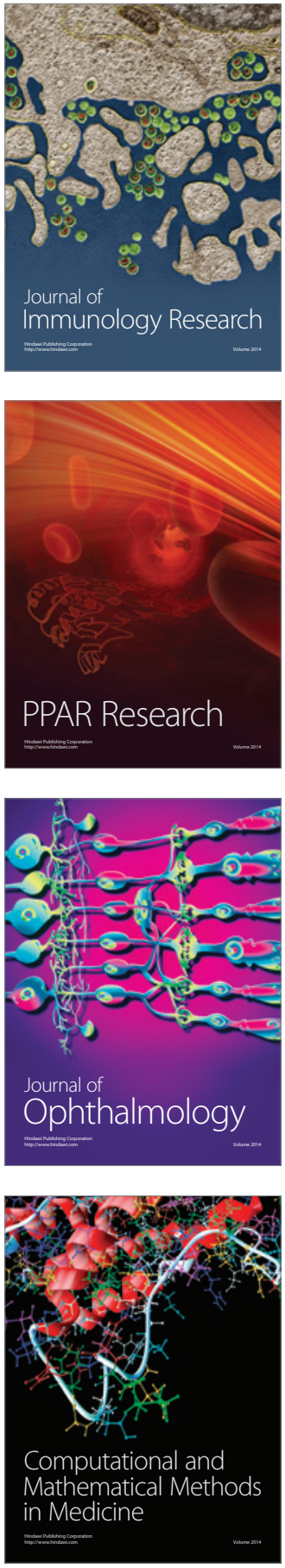

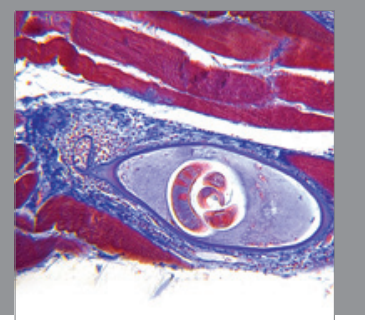

Gastroenterology

Research and Practice
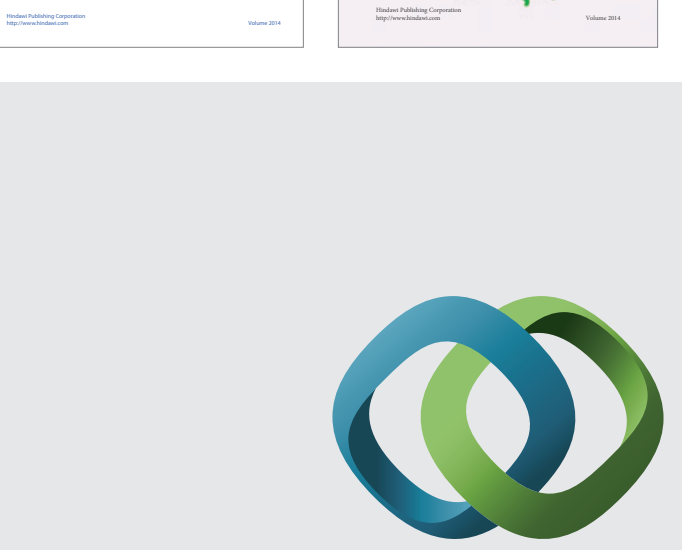

\section{Hindawi}

Submit your manuscripts at

http://www.hindawi.com
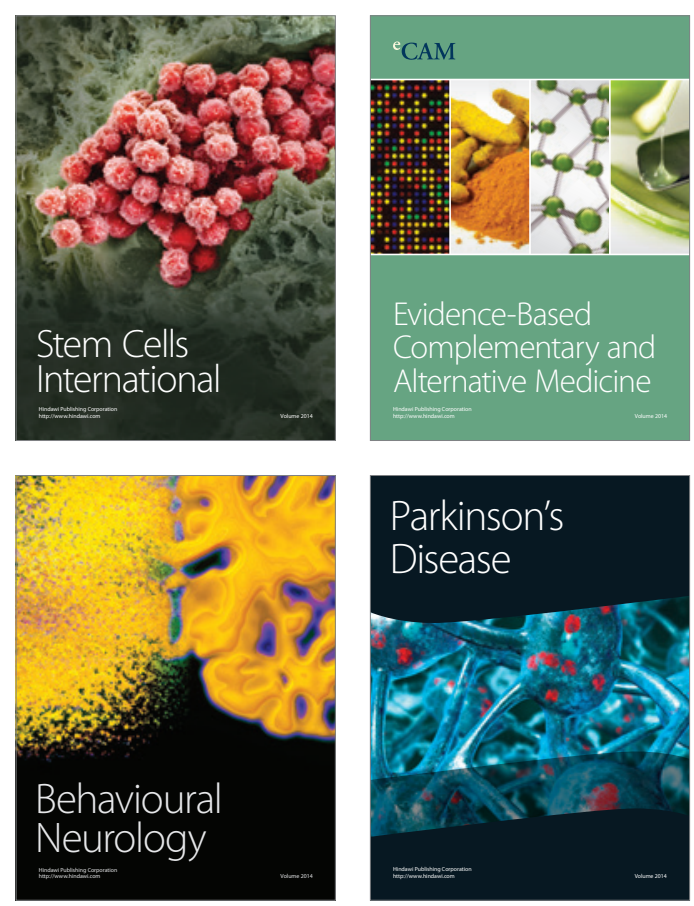

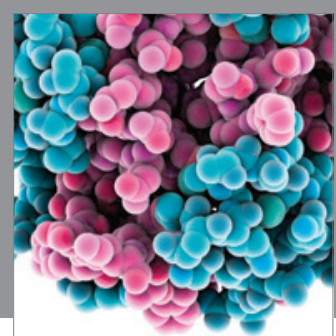

Journal of
Diabetes Research

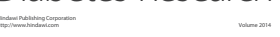

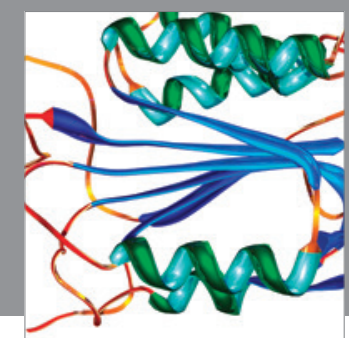

Disease Markers
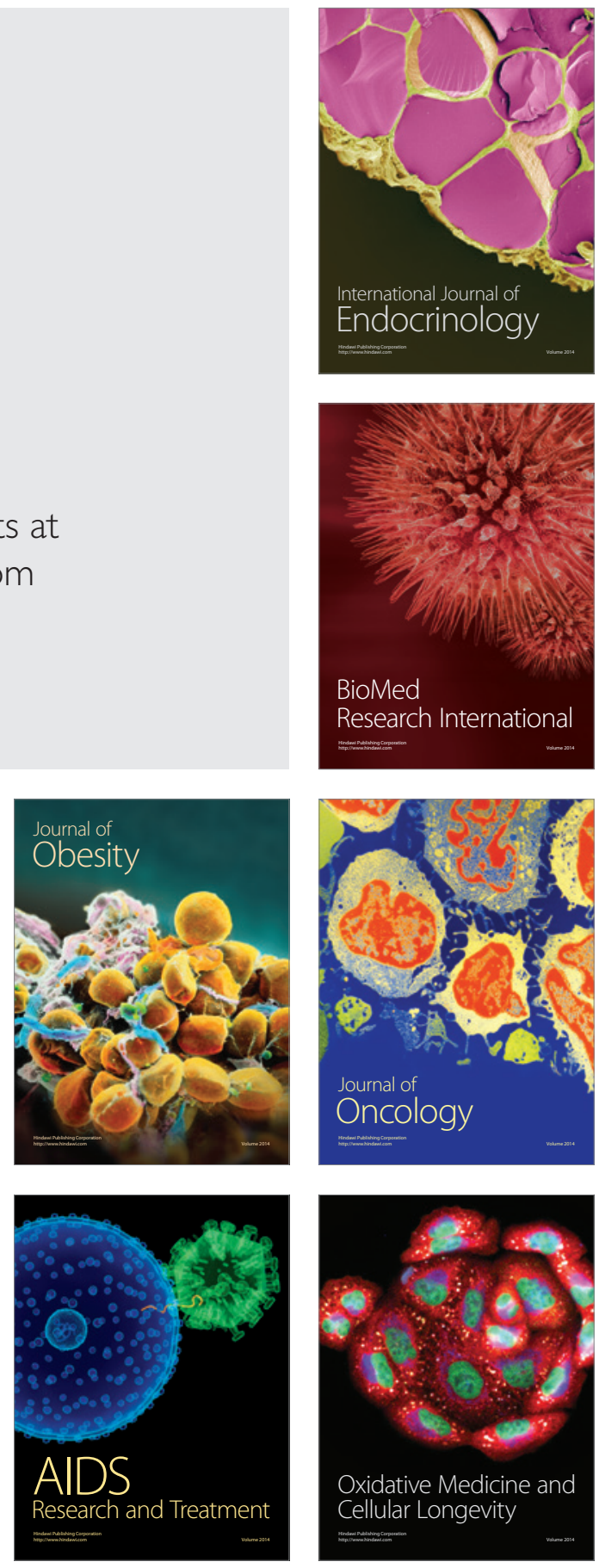